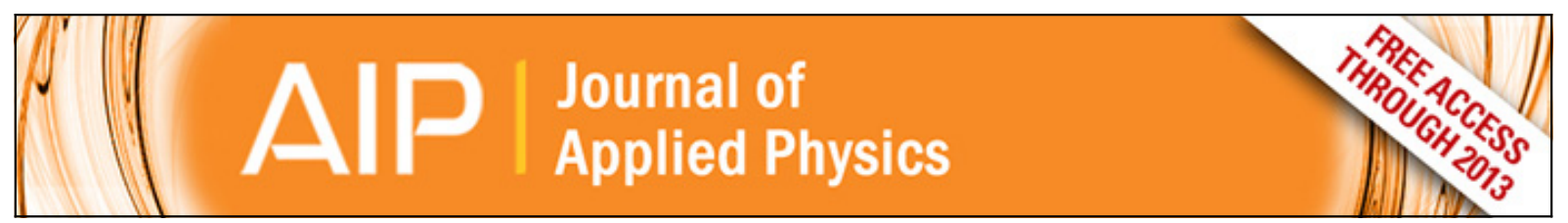

A model for low temperature interface passivation between amorphous and crystalline silicon

J. Mitchell

Citation: Journal of Applied Physics 114, 193702 (2013); doi: 10.1063/1.4824102

View online: http://dx.doi.org/10.1063/1.4824102

View Table of Contents: http://scitation.aip.org/content/aip/journal/jap/114/19?ver=pdfcov

Published by the AIP Publishing

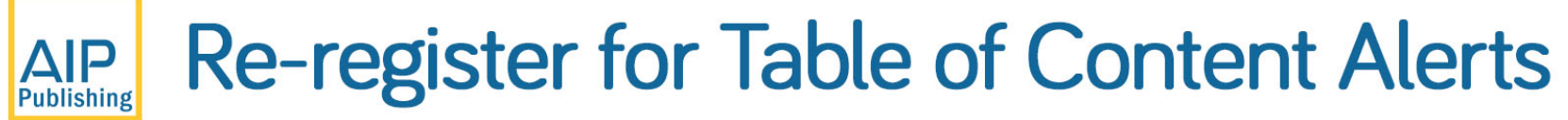




\title{
A model for low temperature interface passivation between amorphous and crystalline silicon
}

\author{
J. Mitchella) \\ The Australian National University, Canberra, ACT 0200, Australia
}

(Received 17 May 2013; accepted 17 September 2013; published online 15 November 2013)

\begin{abstract}
Excellent passivation of the crystalline surface is known to occur following post-deposition thermal annealing of intrinsic hydrogenated amorphous silicon thin-film layers deposited by plasmaenhanced chemical vapour deposition. The hydrogen primarily responsible for passivating dangling bonds at the crystalline silicon surface has often been singularly linked to a bulk diffusion mechanism within the thin-film layer. In this work, the origins and the mechanism by which hydrogen passivation occurs are more accurately identified by way of an interface-diffusion model, which operates independent of the a-Si:H bulk. This first-principles approach achieved good agreement with experimental results, describing a linear relationship between the average diffusion lengths and anneals temperature. Similarly, the time hydrogen spends between shallow-trap states is shown to decrease rapidly with increases in temperature circuitously related to probabilistic displacement distances. The interface reconfiguration model proposed in this work demonstrates the importance of interface states and identifies the misconception surrounding hydrogen passivation of the c-Si surface. (C) 2013 AIP Publishing LLC. [http://dx.doi.org/10.1063/1.4824102]
\end{abstract}

\section{INTRODUCTION}

As crystalline silicon (c-Si) wafers decrease in thickness, the importance of reducing recombination at their surfaces is even more critical for producing high-efficiency solar cells. Passivation of recombination-active electronic states on the c-Si surface is often achieved by their hydrogenation, effectively reducing the density of surface states through the use of a deposited dielectric layer, namely, silicon nitride $\left(\mathrm{SiN}_{\mathrm{x}}\right)$ or amorphous silicon $(\mathrm{a}-\mathrm{Si}: \mathrm{H})$. Therefore, the motion and interaction of hydrogen from within these layers to the c-Si surface are of particular importance for optimising passivation.

For a-Si:H, measured defect densities between $10^{15}$ and $10^{17} \mathrm{~cm}^{-3}$ (Refs. 1 and 2) discourage high concentrations of "free" hydrogen in the deposited films, as a source for hydrogenated passivation of c-Si. Similarly, the spontaneous release of hydrogen under thermal loading, although possible from a 3 -fold Si-configuration at $2.49 \mathrm{eV}$, is also unlikely for low temperature processing conditions. ${ }^{3}$ Subsequently, Pantelides ${ }^{1}$ proposed a condition, where hydrogen from within the thin-film bulk would diffuse with an energy of approximately $1.5 \mathrm{eV}$ towards the unpassivated c-Si surface via a "bond-interconversion" pathway, without the need to break hydrogen bonds. To give explanation towards the improved measured surface recombination velocities $\left(\mathrm{s}_{\text {eff }}\right)$ for c-Si when deposited with a-Si:H or its analogous $\mathrm{SiN}_{\mathrm{x}}$ at all temperatures below $600{ }^{\circ} \mathrm{C},{ }^{4-8}$ numerous experimental and theoretical studies have referred to this trap-limited bulk diffusion model for hydrogen diffusion of the c-Si

\footnotetext{
${ }^{a)}$ Currently with: National Institute for Advanced Industrial Science and Technology, Tsukuba, 305-8568, Japan. Electronic mail: jonathon.micchieru@aist.go.jp
}

surface. ${ }^{9-15}$ Indeed, for much of the past decades, this mechanism has, through reference alone, been assumed to govern passivation through hydrogenation. ${ }^{4-6,16-18}$

Hydrogenated layers with high hydrogen content $(\mathrm{H} \%)$ were initially deemed a necessity to maximise surface passivation, however, higher hydrogen concentrations also resulted in lower measured effective carrier lifetime $\left(\tau_{\text {eff }}\right)$. To overcome this duplicity, thicker films $(>50 \mathrm{~nm})$ with lower $\mathrm{H} \%$ have been as a rule in the past and have been used to increase the supply of hydrogen, without increasing the concentration within the layer. Although HiT solar cells have achieved excellent passivation with very thin intrinsic and doped layers, the relation between hydrogen and passivation for low temperatures is not fully understood.

Notwithstanding the advances in this branch of Photovoltaics, the conception of bulk diffusion does not clarify why preferential diffusion of hydrogen towards the interface would be expected to occur in opposition to other defect-rich regions throughout the bulk of the thin-film layer. Neither does it explain the high quality passivation results achievable using thin $5 \mathrm{~nm}$ a-Si:H(i) layers with $[\mathrm{H}]<10 \%$. Moreover, unlike $\mathrm{SiN}_{\mathrm{x}}$, the "inter-conversion" bulk diffusion mechanism would be significantly compromised by the high defect of the a-Si:H layer deposited within a low temperature regime.

In earlier work, ${ }^{19}$ the lack of good passivation of the c$\mathrm{Si}$ surface for as-deposited a-Si:H layers provided insight into the hydrogenation process, both during deposition and following post-deposition thermal annealing. In particular, thermal annealing was shown to improve the surface state configurations, where the surface states were also found to relax during annealing, likely by lowering the adsorption barrier. ${ }^{20,21}$ Indeed, the energy required to flip an asymmetric Si-dimer into a suitable configuration for hydrogen adsorption is only $0.1 \mathrm{eV}$ for $\mathrm{Si}\langle 100\rangle,{ }^{22}$ although, this process is 
slow and cannot be forced by incident hydrogen during deposition. ${ }^{23}$ The relatively high deposition rate $\left(4 \AA^{-1} s^{-1}\right.$ of our earlier, low temperature work gave insufficient time for the $\mathrm{Si}$ surface to reconfigure ideally for hydrogen adsorption.

To improve our understanding concerning the physical process of c-Si surface passivation driven by hydrogenation, this paper seeks to clarify the ambiguity surrounding the origins of the hydrogen responsible for the significant improvements observed in the electronic quality of the a-Si:H/c-Si interface following earlier, post-deposition thermal anneal experiments.

\section{INTERFACE-DIFFUSION MODEL}

Brenig, Gro $\beta$, and Russ ${ }^{24}$ have proposed a surface state model, which focused on the reconfiguration of surface states since the presence of these in the Si band-gap can lead to the subsistence of the adsorption barrier. As the a-Si:H undergoes structural relaxation during thermal annealing, the contribution of network stress to the height of the absorption barrier is minimal. Hence, incident hydrogen may be adsorbed without experiencing a large barrier, ${ }^{23,25}$ Merging this concept with the work by Tuttle and Adams ${ }^{26}$ Bratu et al.,${ }^{27,28}$ Fedders, ${ }^{29}$ and Street, ${ }^{30}$ it is likely that a mechanism may exist without an indicative dependence on bulkdiffusion. Previous work has determined the activation energy for the surface passivation mechanism to be $0.7 \pm 0.1 \mathrm{eV},,^{19,31,32}$ below the energy typically ascribed for hydrogen diffusion from the thin-film bulk. Alternatively, it is proposed that underpinning the surface passivation process is mechanism for lateral diffusion over the c-Si surface consistent with the transport of hydrogen at low temperatures. Utilising chemisorption and probabilistic based formulae, a model has been developed describing hydrogen interface mobility within the bounds of the above value for $\mathrm{E}_{\mathrm{A}}$. In Figure 1, the essential concept of the model is illustrated.

In this model, hydrogen diffusion occurs laterally on the c-Si surface and beneath the a-Si:H(i) bulk layer by localised hopping of low energy states, where the hydrogen absorbed at one site jumps to another site on the surface via shallow trapping states. As described, hydrogen from intermediate trapping sites with desorption energies $E_{\mathrm{d} 1-3}$ move from trap to intermediate, then to the transport level. Here, quasi-bonded hydrogen laterally diffuse across the c-Si surface, via a series of shallow traps, with energies $\left(\mathrm{E}_{\mathrm{T}}\right)$ between $0.2 \mathrm{eV}$ and $0.4 \mathrm{eV}$ as measured through IR and SIMS spectroscopy. ${ }^{12,33}$ For this, hydrogen is considered mobile between traps through a transport level, and any surface diffusion will be a random walk in 3-dimensions, potentially influenced by phonon scattering. Therefore, hydrogen passivation may be considered a balance between the probabilities of desorption and mobile hydrogen from the a-Si:H being shallow or deeply trapped.

The merit of a low, $0.7 \mathrm{eV}$ thermal activation energy for surface passivation can be assessed by a trapping coefficient $\left(\mathrm{s}_{\mathrm{o}}\right)$. This parameter governs the adsorption of mobile hydrogen at favourable sites, such as dangling bonds (i.e., $\pi$-bond), proportional to the fractional hydrogen coverage $(\theta)$. Typically, the site-limited, low trapping probability of mobile hydrogen characterised by low $\mathrm{s}_{\mathrm{o}}$ describes widespread hydrogen coverage of the c-Si surface, ${ }^{23,34}$ a consequence of the apparently large adsorption barrier near equilibrium when site-blocking is taken into account. As shown in laser-induced desorption experiments, $\mathrm{s}_{\mathrm{o}}$ is thermally activated ${ }^{23}$ and therefore may be expressed according to an Arrhenius-like equation, where site-blocking and $\sigma$-bonds are applicable

$$
s_{o}=A_{o} \exp \left[\frac{-E_{A}}{k_{b} T}\right] .
$$

In this, a pre-exponential factor $\left(\mathrm{A}_{\mathrm{o}}\right)$ of $7 \times 10^{-2} \pm 0.5$ is assumed, ${ }^{23,24}$ with $\mathrm{E}_{\mathrm{A}}$ being the thermal activation energy determined in previous work, ${ }^{35}$ Boltzmann's constant $\left(\mathrm{k}_{\mathrm{b}}\right)$, and substrate temperature $(T)$. For the $\mathrm{Si}\langle 100\rangle$ surfaces in this work, a value for $\mathrm{s}_{\mathrm{o}} \leq 10^{-9}$ is calculated appropriate to $\mathrm{E}_{\mathrm{A}}$ of $0.7 \mathrm{eV}$. This linkage to the thermally activated surface passivation mechanism independent of the a-Si:H bulk hydrogen diffusion ${ }^{19,35}$ would be expected to encourage lower frictional resistances to hydrogen mobility and lower energy requirements due, in part, to the reduced displacement during lateral diffusion.

Similar results have been observed for temperature programmed desorption at higher temperatures, ${ }^{27}$ although Kolasinski et al. (Ref. 23) report a value for $\mathrm{s}_{\mathrm{o}}$ of $4 \times 10^{-6}$ at $300^{\circ} \mathrm{C}$ and Bratu et al. ${ }^{27}$ measured $\mathrm{s}_{\mathrm{o}}$ at approximately $1 \times 10^{-8}$ for $277^{\circ} \mathrm{C}$. For dihydride $\left(\mathrm{SiH}_{2}\right)$ dominant a-Si:H layers, Liehr et al ${ }^{36}$ determined a maximum $\mathrm{s}_{\mathrm{o}}$ of $1 \times 10^{-8}$ for temperatures below $170^{\circ} \mathrm{C}$. It may be concluded from these values that the relative change in $\mathrm{s}_{\mathrm{o}}$ remains small, below $300{ }^{\circ} \mathrm{C}$

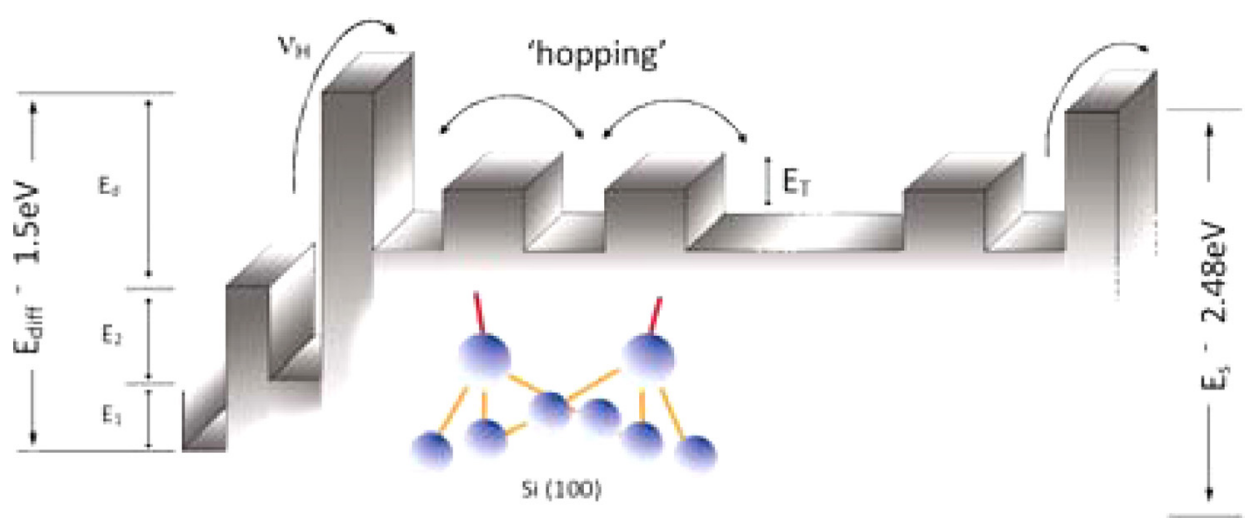

FIG. 1. Diagram of hydrogen desorption and surface diffusion mechanism via shallow trap sites. $\mathrm{E}_{\mathrm{d} 1-3}$ denotes the energy for each desorption configuration of hydrogen, $\mathrm{E}_{\mathrm{T}}$ represents the energy required for "hopping" for the transport level, $\mathrm{E}_{\mathrm{diff}}$ and $\mathrm{E}_{\mathrm{S}}$ denote the energy for bulk diffusion and spontaneous release of hydrogen, respectively, and $v_{\mathrm{H}}$ is the desorption rate. 


\section{A. Dynamic surface states}

If hydrogen surface states are considered dynamic, the surface diffusion of hydrogen can be approximated as pseudo-chemisorption, allowing the hydrogen coverage of the $\mathrm{c}-\mathrm{Si}$ surface to be calculated from the experimentally determined $\mathrm{E}_{\mathrm{A}}$ and calculated $\mathrm{s}_{\mathrm{o}}$. As a part of this model, three principles are first established:

- Adsorption cannot proceed beyond the monolayer coverage;

- All sites are treated as equivalent on a uniform surface;

- The efficacy of hydrogen to be adsorbed at any site remains independent of the occupation of neighbouring sites.

Thus, at any given temperature, $\mathrm{k}_{\mathrm{d}}$ remains constant and hydrogen may remain within the transport layer of the interface region until a trap site, either shallow or deep, is located. Mobile hydrogen transport has been reported to occur across shallow traps with a minimum energy of $0.2 \mathrm{eV}^{37,38}$ If the additional assumption that hydrogen can be sourced from above the monolayer is applied, a reservoir of sourceable hydrogen becomes available, as shown by real-time spectroscopic ellipsometry and spectroscopy, ${ }^{39}$ to effectively passivate the interface invoked by the principle of detailed balance.

According to the Arrhenius determinations for activation energy, a 1st order rate of desorption is initially suited for the $\mathrm{Si}\langle 100\rangle$ surface. $^{40,41}$ From the Polanyi-Wigner equation, the temperature dependent desorption probability $\left(v_{\mathrm{d}}\right)$ can be written as

$$
v_{d}\left(T_{s}\right)=v_{d}^{o} \exp \left(\frac{-E_{A}}{k_{b} T}\right),
$$

where $v_{d}^{o}$ is the prefactor governing desorption (between $10^{14}$ $\mathrm{s}^{-1}$ and $\left.10^{15} \mathrm{~s}^{-1}\right) .{ }^{23,42}$ Accordingly, $\mathrm{k}_{\mathrm{d}}$ can be simplified with respect to the maximum hydrogen coverage giving

$$
k_{d}(\theta)=v_{d}\left(T_{s}\right) \theta^{m},
$$

where $\theta$ is the fractional hydrogen coverage of 0.8 for $\leq 0.14$ $\mathrm{ML}^{23,27,41}$ and $m$ is the reaction order. ${ }^{43}$ However, for the $\mathrm{Si}$ $\langle 100\rangle$ surface, desorption undergoes both 1 st and 2 nd order kinetics due to the presence of two distinct desorption pathways. In the first, desorption of hydrogen occurs from adjacent $\mathrm{Si}$ atoms of a single dimer. ${ }^{41,42}$ For 2 nd order, the formation of a secondary, intermediate dihydride phase, facilitating the desorption process from two monohydrides, occurs simultaneously. ${ }^{44-46}$ Therefore, a variable reaction order is commonly implied for the $\mathrm{Si}\langle 100\rangle$ surface and a value of 1.56 is often chosen, however, through numerical analysis to the previous experimental results a value closer to 1.7 (Refs. 47 and 48) is recommended for an initially unpassivated $\mathrm{c}-\mathrm{Si}$ surface in the presence of hydrogen, accounting for any 2 nd order desorption as well.

\section{B. Dependence of hydrogen surface coverage on desorption}

If surface coverage is determined by the rate of desorption, then, given the barrier to adsorption at a suitable trap site would be minimal, it's influence is negated in this analysis. Equivalent to saying, $\mathrm{k}_{\mathrm{a}}$ will have little influence upon the rate of surface coverage compared to $\mathrm{k}_{\mathrm{d}}$. Therefore, the coverage for deeply trapped hydrogen at any given time would be reliant upon the temperature dependent flux $(\Phi)$ of the desorbed hydrogen linking the release of interstitial hydrogen to surface coverage. For temperature dependent desorption, the probability of mobile hydrogen bonding at any suitable site would be expected to increase as temperature increases. By relating this to the Arrhenius expression for $v_{d}$ (Eq. (2)) and $k_{d}$ (Eq. (3)), midway between 1st and 2nd order kinetics for fractional hydrogen coverage's, $\Phi$ can be expressed according to Eq. (4). Table I briefly lists the results of this calculation for a range of temperatures

$$
\Phi=0.8 \exp \left(\frac{-E_{A}}{k_{b} T}\right) \theta^{m}\left(2 \pi m k_{b} T\right)^{-\frac{1}{2}} .
$$

If the concentration of mobile hydrogen is low, relative to immobile $\mathrm{SiH}$, the coverage dependence of $\mathrm{s}_{\mathrm{o}}$ can be considered constant at any given temperature below $300^{\circ} \mathrm{C}$, until the reaction approaches equilibrium. Relating desorption to a thermally activated chemisorption process, the density of mobile hydrogen will vary linearly with the square root of the concentration. From this, the time-dependent hydrogen coverage $\left(\theta_{\mathfrak{t}}\right)$ can be approximated from the flux of mobile hydrogen $(\Phi)$ for any given pathway and $\mathrm{s}_{\mathrm{o}}$, limited by the total hydrogen coverage according to Fick's law and Kohlrausch's Law ${ }^{49}$ giving

$$
\theta_{(t)}=\theta^{m}\left[1-\exp \left(\frac{-s_{o} \Phi t}{\theta_{(t) \max }}\right)\right],
$$

where $\theta_{(\mathrm{t}) \max }$ is the maximum experimental coverage for the Si surface (approximately $8 \times 10^{14} \mathrm{~cm}^{-2}$ for $\mathrm{Si}\langle 100\rangle^{23,24,50}$ ) with time. This is in-line with the average number of available bonds for the $\langle 100\rangle$ surface of $6.8 \times 10^{14} \mathrm{~cm}^{-2} .{ }^{51}$ As an abundant source of interstitial hydrogen is located at or near the interface, a constant rate of desorption for a chosen anneal temperature can be assumed.

In Figure 2, increases in the effective hydrogen coverage calculated from our model are seen to closely follow improvements in the effective carrier lifetime ${ }^{19}$ resulting from post deposition thermal annealing for a range of temperatures common to a-Si:H processes. As expected, with a fractional coverage, saturation of the c-Si surface occurs at approximately $10^{14} \mathrm{~cm}^{-2}$ following deposition; proceeding rapidly at first, then slowing as suitable sites are reduced. Similar annealing times to achieve "saturation" of the c-Si surface dangling bonds have previously been reported ${ }^{35}$ and suggest the passivation of the c-Si surface is dependent upon the thermal mobility of hydrogen across the interface, a

TABLE I. Calculated desorbed hydrogen flux according to Eq. (4).

\begin{tabular}{lcccc}
\hline \hline Anneal temperature & $185^{\circ} \mathrm{C}$ & $215^{\circ} \mathrm{C}$ & $245^{\circ} \mathrm{C}$ & $275^{\circ} \mathrm{C}$ \\
\hline$\Phi$ & $2 \times 10^{17}$ & $4 \times 10^{17}$ & $1 \times 10^{18}$ & $2 \times 10^{18}$ \\
\hline \hline
\end{tabular}




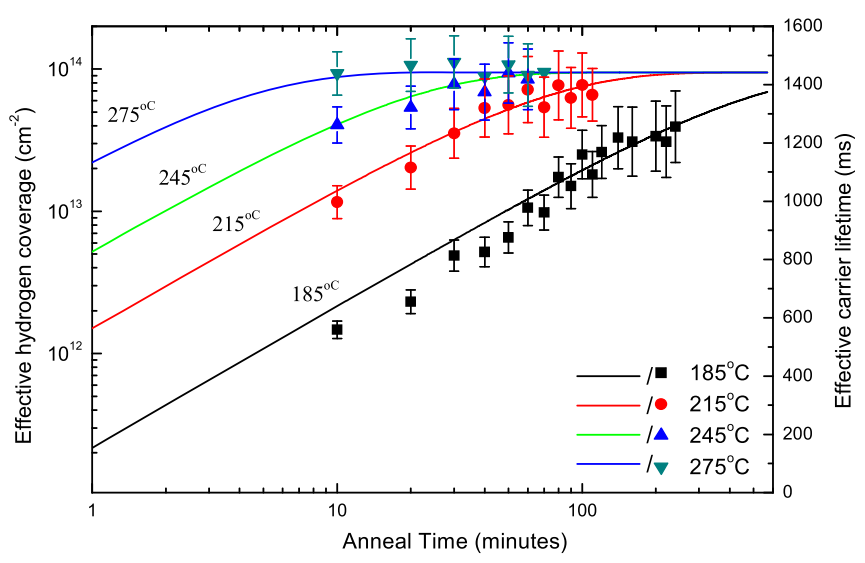

FIG. 2. Effective hydrogen coverage with time (lines) determined from Eq. (2) for a range of post-deposition thermal annealing temperatures and compared to effective carrier lifetime (markers) of a-Si:H(i)/c-Si(n) annealed under similar temperatures. ${ }^{19}$

condition overlooked in the bulk-diffusion process. In describing the two radically different diffusion phenomena, a surface reconfiguration mechanism is more acceptable as being responsible for coverage and passivation of the $\mathrm{c}-\mathrm{Si}$ surface than bulk diffusion.

The trend observed in Figure 2 may aptly be believed to result from a simple increase in the rate of absorption $\left(\mathrm{k}_{\mathrm{a}}\right)$, as the absorption barrier lowers, with disregard to the source of the hydrogen. However, for surface based reactions, the observed trend should instead be considered the result of increases to the rate of desorption $\left(\mathrm{k}_{\mathrm{d}}\right)$ relative to $\mathrm{k}_{\mathrm{a}}$, of interstitially-trapped hydrogen (i.e., $\mathrm{k}_{\mathrm{a}} \ll \mathrm{k}_{\mathrm{d}}$ ) with an already inconsequential absorption barrier. Essentially, the probability of interstitial hydrogen being desorbed and diffusing laterally across the interface must be considered. In this, hydrogenation of the c-Si surface would proceed rapidly within the first few minutes, as observed in Figure 2, due to the increased desorption rate and availability of absorption sites (high $\mathrm{s}_{\mathrm{o}}$ ).

For hydrogen, the probability of having sufficient energy to overcome the dissociation barrier and undergo lateral diffusion can be expected to increase rapidly with temperature. Hence, the rate of adsorption with negligible barrier can be considered dependent upon the rate of desorption, regulated only by the current c-Si surface coverage, the anneal temperature, and the time required for hydrogen to locate a trapping site. This would be the case when hydrogen, located at interstitial bonding sites within the interface region, is sufficient for full coverage of the c-Si surface. For this, a reconfigured surface state occurs.

\section{Mobile hydrogen diffusion}

To understand what is occurring to hydrogen at the a$\mathrm{Si}: \mathrm{H} / \mathrm{c}-\mathrm{Si}$ interface during c-Si surface reconfiguration, the diffusion coefficient for mobile hydrogen $\left(D_{m}\right)$ is determined by an Arrhenius-like expression relating to the thermally activated surface passivation. Here, $E_{H}$ is the energy for hydrogen release equal to the interstitial potential well energy, approximately $0.31 \mathrm{eV}^{2,23}$ The pre-exponential factor $\mathrm{D}_{\mathrm{o}}=\left(2 v_{\mathrm{o}} a^{2}\right) / 3^{52}$ is roughly equivalent to the value for hydrogen diffusion for the c-Si surface $\left(5 \times 10^{-3} \mathrm{~cm}^{2} \mathrm{~s}^{-1}\right)$ in agreement with the literature ${ }^{14,23}$

$$
D_{m}=D_{o} e^{\frac{-E_{H}}{k_{b} T}}
$$

Remembering the diffusion of hydrogen laterally across the c-Si surface is assumed trap-limited, being typically terminated by capture at any deep-trapping site (i.e. passivation of a dangling bond). Given mobile hydrogen concentrations are small compared to immobile hydrogen, ${ }^{53}$ the interdependence is defined by

$$
N_{m} D_{m}=N_{H} D_{H}
$$

where $\mathrm{N}_{\mathrm{m}}$ is the mobile hydrogen density (i.e., flux), $\mathrm{N}_{\mathrm{H}}$ is the immobile hydrogen density for a-Si:H (i.e. $5 \times 10^{21} \mathrm{~cm}^{-3}$ ), and the effective hydrogen diffusion coefficient $\left(\mathrm{D}_{\mathrm{H}}\right)$ is $2 \times 10^{-18} \mathrm{~cm}^{2} \mathrm{~s}^{-1} \cdot 53$ As hydrogen within the a-Si:H bulk remains deeply trapped, the value of $\mathrm{D}_{\mathrm{H}}$ should remain low. ${ }^{35}$ For a random-walk in 3-dimensions, the hydrogen diffusion coefficient can be written as

$$
D_{H}=\left(\frac{v_{H}^{o}}{6 a N_{d b}}\right) \exp \left(\frac{-E_{H}}{k_{b} T}\right),
$$

where $v_{H}^{o}$ is the emission rate of mobile hydrogen per $\mathrm{Si}-\mathrm{H}$ pair at a given temperature, $a$ is the average distance between deep-trapping sites $\left(2.3 \times 10^{-8} \mathrm{~cm}\right),{ }^{17,23,54}$ and $\mathrm{N}_{\mathrm{db}}$ is the dangling bond density $\left(10^{16} \mathrm{~cm}^{-3}\right)^{2,53}$ for temperatures between $190{ }^{\circ} \mathrm{C}$ and $300{ }^{\circ} \mathrm{C}$. As the distance between traps is only a few nanometres, the initial coverage rates following post-deposition thermal annealing are expected to be high. Also noting that less energy is required for the smaller displacement which Hydrogen undergoes.

In Figure 3, the effective hydrogen flux is seen to increase rapidly as the anneal temperature increases. As $\Phi$ increases with temperature, $\mathrm{N}_{\mathrm{m}}$ (i.e., transport level density) decreases due to increases in $\mathrm{D}_{\mathrm{m}}$. To understand this apparent contradiction, we consider $\Phi$ not as a measure of hydrogen in the transport level itself, but rather an average of the hydrogen moving between sites in the transport level.

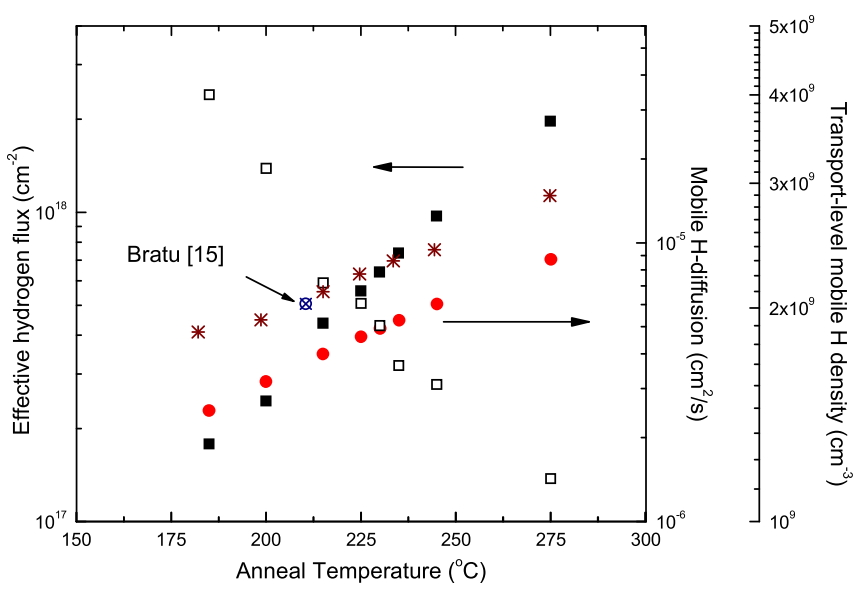

FIG. 3. ( $\Phi)$ effective hydrogen flux (solid squares), $\left(\mathrm{N}_{\mathrm{m}}\right)$ transport-level mobile hydrogen density (hollow squares), and $\left(\mathrm{D}_{\mathrm{m}}\right)$ mobile hydrogen diffusion coefficient (circles). Calculated $\mathrm{D}_{\mathrm{m}}$ without $\mathrm{SiH}_{2}$ compensation (stars). 
Therefore, the adsorption occurs rapidly relative to desorption and we can expect $\theta$ to approach saturation quickly for higher temperatures as the probability of hydrogen becoming trapped by a dangling bond increases with temperature. Branz reported a similar value of $\mathrm{D}_{\mathrm{m}}$ for mobile hydrogen within the transport level at $210^{\circ} \mathrm{C}^{15}$ using a lower value for $v_{\mathrm{o}}$ and higher $\mathrm{E}_{\mathrm{A}}$, resulting in a calculated $\mathrm{N}_{\mathrm{m}}$ one order in magnitude higher than in this work. In Figure 3, the effect $\mathrm{SiH}_{2}$ in secondary pathways can have on uncompensated calculations for $D_{m}$ is displayed, consequently effecting $N_{m}$. For the result reported by Branz, it may be concluded that no account for the presence of $\mathrm{SiH}_{2}$ within a secondary intermediate pathway was made.

\section{Diffusion lengths and transport time}

With $\mathrm{D}_{\mathrm{H}}$ determined from Eq. (8), the average lateral diffusion length of mobile hydrogen in the transport level may also be calculated according to the kinetic formula for diffusion, where the diffusion length of hydrogen between traps $\left(\lambda_{\mathrm{H}}\right)$ is determined

$$
D_{H}=v_{H} \lambda_{H}^{2}
$$

In this, the displacement is assumed to correspond to deeptraps only, as shallow trap pathways are considered infinite. Figure 4 gives the mean distance hydrogen may travel across the $\mathrm{c}$-Si surface, exhibiting a linear relationship with increases in the thermal anneal temperature up to $300^{\circ} \mathrm{C}$.

Similarly, the average time spent by mobile hydrogen in the transport level prior to being trapped by a dangling bond can be approximated from the Einstein-Smoluchowski equation (Eq. (10)) for diffusion. This associates the individual details regarding particle motion with the microscopic parameters relating to diffusion (i.e., linking the diffusion coefficient and Stokes-Einstein $)^{49}$

$$
D_{H}=\frac{\lambda_{H}^{2}}{2 \tau_{H}}
$$



FIG. 4. Mean diffusion length of hydrogen $\left(\lambda_{t}\right)$ according to Eq. (9) before becoming trapped at a deep-defect (squares) and the average time of hydrogen $\left(\tau_{\mathrm{H}}\right)$ spent between deep trapping sites (triangles) from Eq. (10).
The average hopping time $\left(\tau_{\mathrm{H}}\right)$ for mobile hydrogen between traps can be calculated from this, with the results shown in Figure 4.

It is surmised that, for the anneal temperatures studied in this work, hydrogen within the first few mono-layers is capable of moving across the c-Si surface or from the nearinterface region to passivate a dangling bond. Furthermore, bulk hydrogen diffusion, although noteworthy in high temperature processes, is not suited to explain c-Si surface passivation as observed in annealing experiments at lower temperatures, provided sufficient hydrogen is available near the interface.

\section{E. Composition of $E_{A}$}

In considering a surface, which reconfigures to accept laterally diffusing hydrogen, and where surface states in the $\mathrm{Si}$ band-gap may reduce the adsorption barrier to hydrogen by increasing the $\mathrm{Si}-\mathrm{Si}$ bond lengths during adsorption, ${ }^{27}$ only three types of transitions are relevant here:

1. Transport between traps within transport level,

2. from the transport level, and

3. to the transport level.

Given the energy to overcome the potential barrier for dissociation from an interstitial site to a mobile site remains constant, one supposition of our model is that the calculated value for $\mathrm{E}_{\mathrm{A}}$ of $0.7 \pm 0.1 \mathrm{eV}$ may represent the sum of different energies for each of the above transitions, and may in part explain the slow, but eventual passivation of the c-Si surface by a-Si:H below $200^{\circ} \mathrm{C}^{35}$ As the thermal anneal temperature is increased, the probability for mobile hydrogen to continue to diffuse across the c-Si surface until a suitable deep trap is located also increases, as does the probability of interstitial hydrogen overcoming the dissociation potential. As previously stated, the minimum energy required for hopping of mobile hydrogen across shallow traps $\left(E_{H}\right)$ is approximately $0.2 \mathrm{eV} .^{55}$ Similarly, the energy required for hydrogen to overcome the dissociation potential barrier for interstitial bonding $\left(\mathrm{E}_{\mathrm{i}}\right)$ has been reported to be approximately $0.48 \mathrm{eV}$ from ESR experiments. ${ }^{31}$ The aggregate difference, referred here to as residual energy $\left(E_{R}\right)$, may either participate in the transport mechanism or relaxation of $\mathrm{Si}-\mathrm{H}$ bonds during adsorption. From this, $\mathrm{E}_{\mathrm{A}}$ can be described according to

$$
E_{A}=E_{H}+E_{I}+E_{R} .
$$

In this way, $\mathrm{E}_{\mathrm{R}}$ may conceived as assisting the probability that hydrogen will diffuse across the c-Si surface, and also being adsorbed at different trapping sites relating to the relaxation energy of the Si-H bond (Figure 5).

The proposed surface diffusion mechanism for hydrogen is consistent with interstitial transport of hydrogen with a distribution for $\mathrm{E}_{\mathrm{A}}$ over a range of $0.2-0.5 \mathrm{eV}$, as reported in Refs. 12 and 33. The differences in these energies would be accounted for by $E_{R}$ if a low or negligible adsorption barrier is assumed, although its exact nature remains unknown. ${ }^{37,38,56}$ 




FIG. 5. Comparison between energy of mobile H-release (squares) and residual energy (circles) available for hopping mechanism with temperature.

\section{CONCLUSION}

In this work, hydrogenation was studied from the viewpoint of passivating the c-Si surface by considering the activation energy and a mobile hydrogen surface transport process. Proposed is a surface-limited transport mechanism likely responsible for the passivation of the c-Si surface by hydrogen. Below $300^{\circ} \mathrm{C}$, a linear relationship exists between the diffusion distance and the anneal temperature, inconsistent with a bulk diffusion-limited mechanism. In describing the two radically different phenomena, it is reasonable to conclude the latter may simply have masked the underlying surface-reaction mechanism responsible for passivation of the c-Si surface. Quantifying the activation energy for surface passivation (i.e., $0.7 \mathrm{eV}$ ) in terms of the trapping coefficient and hydrogen coverage, the surface-diffusion model should therefore be independent of bulk a-Si:H diffusion, where $\mathrm{E}_{\mathrm{A}}$ is most likely comprised of the energies for three fundamental surface processes.

Correlations between increases in the thermal anneal temperature and the mean interface diffusion length of hydrogen have been shown, describing a mechanism where the probability of mobile hydrogen having an average energy sufficient to transport itself from an interstitial site to a deep trap increases with temperature.

\section{ACKNOWLEDGMENTS}

This work was supported by the Australian Research Council.

${ }^{1}$ S. T. Pantelides, Phys. Rev. Lett. 58(13), 1344 (1987).

${ }^{2}$ S. Zafar and E. A. Schiff, Phys. Rev. Lett. 66(11), 1493 (1991).

${ }^{3}$ W. R. Wampler, S. M. Myers, and D. M. Follstaedt, Phys. Rev. B 55(19), 13319 (1997).

${ }^{4}$ B. L. Sopori, X. Deng, J. P. Benner, A. Rohatgi, P. Sana, S. K. Estreicher, Y. K. Park, and M. A. Roberson, Sol. Energy Mater. Sol. Cells 41-42, 159-169 (1996).

${ }^{5}$ A. G. Aberle, Prog. Photovoltaics 8(5), 473-487 (2000).

${ }^{6} \mathrm{~S}$. Dauwe, J. Schmidt, and R. Hezel, in Proceedings of the 29th IEEE Photovoltaic Specialists Conference, New Orleans, 2002.

${ }^{7}$ H. F. W. Dekkers, S. De Wolf, G. Agostinelli, F. Duerinckx, and G. Beaucarne, Sol. Energy Mater. Sol. Cells 90(18-19), 3244-3250 (2006).
${ }^{8}$ J. Dupuis, E. Fourmond, J. F. Lelièvre, D. Ballutaud, and M. Lemiti, Thin Solid Films 516(20), 6954-6958 (2008).

${ }^{9}$ D. E. Carlson and C. R. Wronski, Appl. Phys. Lett. 28, 671-673 (1976).

${ }^{10}$ H. M. Branz, Phys. Rev. B 39(8), 5107 (1989).

${ }^{11}$ P. V. Santos, N. M. Johnson, and R. A. Street, Phys. Rev. Lett. 67(19), 2686 (1991).

${ }^{12}$ W. B. Jackson and C. C. Tsai, Phys. Rev. B 45(12), 6564 (1992).

${ }^{13}$ H. M. Branz, S. E. Asher, and B. P. Nelson, Phys. Rev. B 47(12), 7061 (1993).

${ }^{14}$ M. Kemp and H. M. Branz, Phys. Rev. B 52(19), 13946 (1995).

${ }^{15}$ H. M. Branz, Phys. Rev. B 60(11), 7725 (1999).

${ }^{16}$ R. A. Street and K. Winer, Phys. Rev. B 40(9), 6236-6249 (1989).

${ }^{17}$ B. Tuttle, C. G. Van de Walle, and J. B. Adams, Phys. Rev. B 59(8), 5493-5497 (1999).

${ }^{18}$ A. H. M. Smets, W. M. M. Kessels, and M. C. M. van de Sanden, Appl. Phys. Lett. 82(6), 865-867 (2003).

${ }^{19}$ J. Mitchell, D. Macdonald, and A. Cuevas, in Proceedings of the 22nd European Photovoltaic Solar Energy Conference (Milan, Italy, 2007).

${ }^{20}$ A. Vittadini, A. Selloni, and M. Casarin, Surf. Sci. 289(3), L625-L630 (1993).

${ }^{21}$ Y. Wang, M. Shi, and J. W. Rabalais, Phys. Rev. B 48(3), 1678 (1993).

${ }^{22}$ R. Dewarrat and J. Robertson, in Proceedings of the MRS Spring Meeting, San Francisco, USA, 2002.

${ }^{23}$ K. W. Kolasinski, W. Nessier, K.-H. Bornscheuer, and E. Hasselbrink, J. Chem. Phys. 101, 7082 (1994).

${ }^{24}$ W. Brenig, A. Gross, and R. Russ, Zeitschrift für Phys. B Condens. Matter 96(2), 231-234 (1994).

${ }^{25}$ K. W. Kolasinski, W. Nessler, A. de Meijere, and E. Hasselbrink, Phys. Rev. Lett. 72(9), 1356 (1994).

${ }^{26}$ B. Tuttle and J. Adams, Phys. Rev. B 57(20), 12589-12868 (1998).

${ }^{27}$ P. Bratu, K. L. Kompa, and U. Höfer, Chem. Phys. Lett. 251(1-2), 1-7 (1996).

${ }^{28}$ P. Bratu, W. Brenig, A. Gro $\beta$, M. Hartmann, U. Höfer, P. Kratzer, and R. Russ, Phys. Rev. B 54(8), 5978 (1996).

${ }^{29}$ P. A. Fedders, Phys. Rev. B 61(23), 15797 (2000).

${ }^{30}$ R. A. Street, Hydrogenated Amorphous Silicon (Cambridge University Press, 1991).

${ }^{31}$ D. K. Biegelsen, N. M. Johnson, M. Stutzmann, E. H. Poindexter, and P. J. Caplan, Appl. Surf. Sci. 22-23, 879-890 (1985).

${ }^{32}$ S. De Wolf and M. Kondo, Appl. Phys. Lett. 90(4), 042111-042113 (2007).

${ }^{33}$ M. Nakamura, T. Ohno, K. Miyata, N. Konishi, and T. Suzuki, J. Appl. Phys. 65(8), 3061-3068 (1989).

${ }^{34} \mathrm{P}$. Nachtigall and K. Jordan, J. Chem. Phys. 102, 8249-8254 (1995).

${ }^{35}$ J. Mitchell, D. Macdonald, and A. Cuevas, Appl. Phys. Lett. 94(16), 162102 (2009).

${ }^{36}$ M. Liehr, C. M. Greenlief, M. Offenberg, and S. R. Kasi, J. Vac. Sci. Technol. A 8 (3), 2960-2964 (1990).

${ }^{37}$ F. Buda, G. L. Chiarotti, R. Car, and M. Parrinello, Phys. Rev. Lett. 63(3), 294 (1989).

${ }^{38}$ C. G. Van de Walle, P. J. H. Denteneer, Y. Bar-Yam, and S. T. Pantelides, Phys. Rev. B 39(15), 10791 (1989).

${ }^{39}$ H. Fujiwara, Y. Toyoshima, M. Kondo, and A. Matsuda, Phys. Rev. B 60(19), 13598 (1999).

${ }^{40}$ K. Sinniah, M. G. Sherman, L. B. Lewis, W. H. Weinberg, J. T. Yates, and K. C. Janda, Phys. Rev. Lett. 62(5), 567 (1989).

${ }^{41}$ M. L. Wise, B. G. Koehler, P. Gupta, P. A. Coon, and S. M. George, Surf. Sci. 258(1-3), 166-176 (1991).

${ }^{42}$ U. Höfer, L. Li, and T. F. Heinz, Phys. Rev. B 45(16), 9485 (1992).

${ }^{43}$ G. A. Reider, U. Hofer, and T. F. Heinz, J. Chem. Phys. 94, 4080-4083 (1991).

${ }^{44}$ C. J. Wu, I. V. Ionova, and E. A. Carter, Surf. Sci. 295(1-2), 64-78 (1993).

${ }^{45}$ P. Gupta, V. L. Colvin, and S. M. George, Phys. Rev. B 37(14), 8234 (1988).

${ }^{46}$ P. Nachtigall, K. D. Jordan, and K. C. Janda, J. Chem. Phys. 95(11), 8652-8654 (1991).

${ }^{47}$ T. Lauinger, J. Moschner, A. G. Aberle, and R. Hezel, J. Vac. Sci. Technol. A 16(2), 530-543 (1998).

${ }^{48} \mathrm{H}$. Sakata, in Proceedings of the 29th IEEE Photovoltaic Specialists Conference (PVSC), Anchorage, 2000. 
${ }^{49}$ P. Atkins and J. de Paula, in Physical Chemistry, edited by J. Crowe, J. Fiorillo, and R. Hughes (Oxford University Press, W.H. Freeman and Co, Oxford, New York, 2006), Vol. 1, p. 1100.

${ }^{50}$ J. Law, J. Chem. Phys. 30(6), 1568 (1959).

${ }^{51}$ S. E. Sze and K. N. Kwok, in Physics of Semiconductor Devices, 3rd ed. (Wiley \& Sons, New Jersey, 2007), p. 221.
${ }^{52}$ H. M. Branz, Phys. Rev. B 59(8), 5498 (1999).

${ }^{53}$ M. Kemp and H. M. Branz, Phys. Rev. B 47(12), 7067 (1993).

${ }^{54}$ Z. Jing and J. L. Whitten, Phys. Rev. B 48(23), 17296-17300 (1993).

${ }^{55}$ J. Robertson, J. Appl. Phys. 87(5), 2608-2617 (2000).

${ }^{56} \mathrm{~A}$. Van Wieringen and N. Warmoltz, Physica 22(6-12), 849-865 (1956). 